\title{
Strategic Plan for the Achievement of the Competitiveness of Small Companies with Respect to Large Ones
}

\author{
Alan Guadalupe Ochoa Navarro*, Juan De Dios Cota Apodaca, Dario Fuentes Guevara
}

National Technological Institute of Mexico / I.T. Los Mochis, 81259, Mexico

\begin{tabular}{l} 
A R T I C L E I N F O \\
\hline Article history: \\
Received: 08 July, 2020 \\
Accepted: 07 October, 2020 \\
Online: 20 November, 2020 \\
\hline Keywords: \\
Strategic plan \\
Competitiveness \\
MSMEs \\
Large companies
\end{tabular}

\begin{abstract}
A B S T R A C T
The main objective of this research is to analyze the impact that the implementation of a strategic plan would have on achieving the competitiveness of the micro, small and medium enterprises (MSMEs) that are dedicated to bottling, marketing and distributing water in the city of Los Mochis. It is intended to offer a tool to this type of company that allows them to be competitive against large transnational companies, which currently dominate the market. For this, a mixed methodology was used, presenting a descriptive-correlational scope with a non-experimental cross-sectional design; In which a population of 21 MSMEs was analyzed, through the application of a measurement instrument, to quantify the levels of competitiveness that they currently present. The results of the investigation showed a low performance in the competitiveness of these businesses, exposing similarities between their deficiencies, highlighting the mismanagement and ignorance of the economic environment in which they are found.
\end{abstract}

\section{Introduction}

Talking about the importance of the micro, small and medium enterprises (MSMEs) is essential to understand the economic growth and development they generate in the world and the positive impact they provide to the global economy, since they generate jobs, pay social security contributions, and also boost local economies; In the opposite case, the large transnational companies that, although they contribute the aforementioned, also return their profits to their country of origin. Likewise, according to [1], more than $99.8 \%$ of the companies in Mexico are micro, small or medium-sized, while in [2] it is indicated that MSMEs contribute $60 \%$ of the GDP of that country.

However, the low level of competitiveness that these small businesses present, represent into a relatively short life span, (since according to [3], only $25 \%$ of these companies survive the first 2 years after opening, while the average life span is around 7 years), in which they fail to compete with the large transnational companies. In other words, the vast majority of these small businesses fail and subsequently disappear from the market. That is why the need arises to offer tools and methodologies that, through interdisciplinary actions, allow MSMEs to achieve competitiveness in the area.

For the above, it is essential to understand the low competitiveness of MSMEs and the context in which they currently compete, as well as the critical factors that directly

${ }^{*}$ Corresponding Author: Alan Ochoa, alanochoa1115@outlook.com influence their low performance, and based on this, determine which strategies are the most appropriate in the design of the strategic plan, given the imminent crisis that threatens these small businesses with their disappearance.

\section{Method and Materials}

\subsection{Type of investigation}

According to the problem detected, it was determined that the research pursues a mixed route since, through both quantitative and qualitative tools, it aims to interpret the scenarios or contexts in which MSMEs are currently, understanding the importance they represent for the economy from any country.

\subsection{Design and scope of the investigation}

The situation for many MSMEs is critical, as they do not show any signs of competitiveness in the market in which they participate, compared to their direct competitors, therefore they do not represent any risk for large companies.

Therefore, this research presents a descriptive-correlational scope with a non-experimental cross-sectional design, on the implementation of a strategic plan in the region's MSMEs, since as in [3], it will be carried out in a period of unique time, trying to shorten the gap between the demand presented by the large brands of bottled water that operate in the region, and the micro and small companies that are dedicated to marketing a similar product. Also, 
only those MSMEs that are dedicated to the bottling and marketing of water in the region will be taken into account.

\subsection{Hypothesis}

The information to formulate the hypothesis arises from the diagnosis obtained, as well as from the reviewed literature, which helps to suppose scenarios in relation to the results that will be obtained, and the significant contributions that the strategic plan will have to the competitiveness of the companies. MSMEs, as well as the adaptability that these businesses and their possible contexts may present.

That said, the following research hypothesis is established:

- Hi. The design of a strategic plan will allow small companies to become competitive with large companies.

\subsection{Design of the instrument}

The instrument used to measure competitiveness in MSMEs in the region was a questionnaire with a Likert-type scale, using the dimensions and indicators of the competitiveness map of the Inter-American Development Bank (IDB) for their reliability, in addition to being a tool widely used by other researchers according to the literature reviewed.

This instrument was used during the development of this research and according to [4], this tool was designed to specifically identify the deficient areas that directly influence the low level of competitiveness of MSMEs, and with this, develop corrective strategies that allow to significantly improve the competitiveness of the diagnosed company. The application consisted of a structured questionnaire used by [5] with a Likert scale, with a total of 103 questions focused on each of the dimensions and indicators established by the IDB competitiveness map.

In addition, according to [6], the Inter-American Development Bank has always contributed to the socioeconomic development of Latin America and the Caribbean, promoting research and supporting companies, which is why it is considered to be a fairly reliable tool, based on the experience of such an organization.

It should be mentioned that as in [7], the dimensions and their respective indicators according to the IDB Competitiveness Map are shown in the Table 1.

Table 1: Dimensions and indicators to measure competitiveness according to the IDB Competitiveness Map:

\begin{tabular}{|ll|}
\hline Variables & Indicators \\
& 1.1 Strategic planning process \\
& 1.2 . Strategy implementation \\
\hline 2. Production and purchases & $2.1 \quad$ Planning and production \\
& process \\
& 2.2. Process capacity \\
& 2.3 Maintenance \\
& 2.4 Research and development \\
& 2.5 Provisioning \\
& 2.6 Inventory management \\
& 2.7 Location and infrastructure \\
& 3.1 General aspects of quality \\
& 3.2 Quality systems \\
\hline 3. Quality Assurance &
\end{tabular}

\begin{tabular}{|c|c|}
\hline 4. Marketing & $\begin{array}{l}\text { 4.1 National market: marketing and } \\
\text { sales } \\
\text { 4.2 National market: services } \\
\text { 4.3 National market: distribution }\end{array}$ \\
\hline 5. Accounting and finances & $\begin{array}{l}\text { 5.1 Cost monitoring and accounting } \\
\text { 5.2 Financial administration } \\
\text { 5.3 Legal and tax regulations }\end{array}$ \\
\hline 6. Human resources & $\begin{array}{l}\text { 6.1 General aspects } \\
6.2 \text { Training and promotion of } \\
\text { personnel } \\
6.3 \text { Organizational culture } \\
6.4 \text { Industrial health and safety }\end{array}$ \\
\hline 7. Environmental management & $\begin{array}{l}\text { 7.1 Environmental policy of the } \\
\text { company } \\
7.2 \text { Strategy to protect the } \\
\text { environment } \\
7.3 \text { Awareness and training of staff } \\
\text { on environmental issues } \\
7.4 \text { Waste management }\end{array}$ \\
\hline 8. Information systems & $\begin{array}{l}\text { 8.1 System planning } \\
\text { 8.2 Inputs } \\
\text { 8.3 Processes } \\
\text { 8.4 Outputs }\end{array}$ \\
\hline
\end{tabular}

Source: Own elaboration, based on Saavedra, Milla and Tapia [1].

Subsequently, once the vulnerable areas of these small businesses have been identified, a strategic plan will be made based on the comprehensive strategic management model [8], which allows them to take the necessary actions, so that they achieve competitiveness with respect to their major competitors.

\subsection{Population}

The population obtained for this research is 21 of MSMEs that are dedicated to bottling and marketing of water in the city of Los Mochis. Likewise, the unit of analysis for this research consists solely of the owners of said MSMEs, due to their knowledge in all areas and their authority to make decisions.

\section{Results}

The results obtained yielded some of the following data:

- Of the 21 MSMEs diagnosed, only 2 businesses acknowledged having used some type of strategic planning in the last 2 years, which represents $9.52 \%$ of the total companies analyzed, while $66.67 \%$ said they have never used strategic planning, running your business solely empirically, as shown in Figure 1.

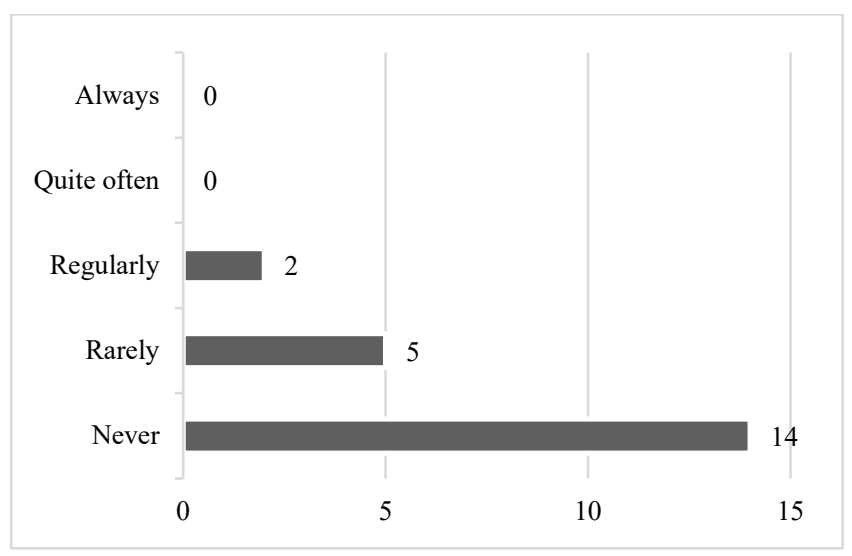

Figure 1: MSMEs that have used strategic planning in the last 2 years. 
This indicates that the MSMEs considered for this research are usually empirically guided, so there is no basis in the decisions they make. This indicates that a series of actions can be offered with analytical support, on what actions to take and find the advantages of implementing them.

- From the same diagnosis, it was found that $61.90 \%$ never implemented a SWOT analysis to identify their strengths and weaknesses, or to better understand the environment in which they compete and their direct competition. A graph with percentages is shown in Figure 2.

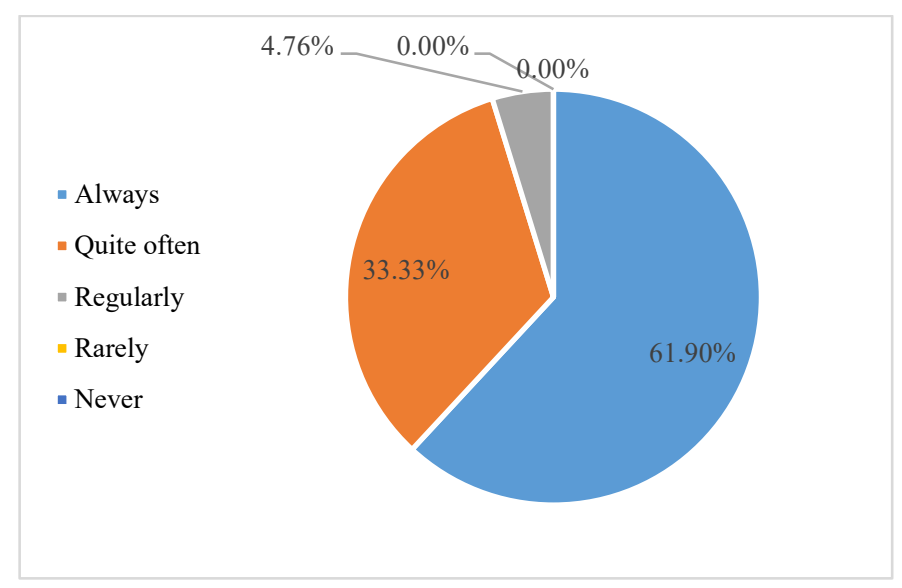

Figure 2: MSMEs that have used SWOT

This result shows that 13 of the 21 MSMEs do not know what their opportunities and threats are in the environment in which they currently compete, and they do not know the strengths they have, or at least not in an analytical and conscious way.

- A very important factor is the care of the work equipment, and in this sense, 17 of the 21 MSMEs admitted not to carry out preventive care to the production teams, which represent into $80.95 \%$ of the total of the companies studied. This percentage is expected to decrease to at least $50 \%$ since this point is considered to be extremely relevant, since without the production equipment in optimal conditions, the operation of the business may be affected in the short term. It can be seen in Figure 3.

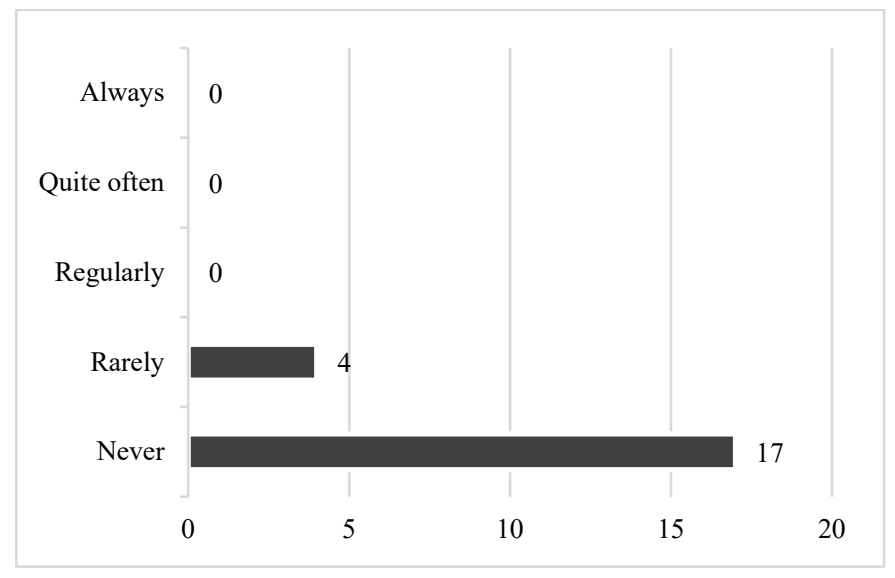

Figure 3: Preventive maintenance program for all equipment and machinery in MSMEs
Based on the previous graph, it can be seen that most MSMEs do not take optimal care of work tools, which will affect these businesses a lot, since the operation and production of the product depends on this.

- There is mismanagement of inventories by diagnosed MSMEs, since $76.19 \%$ of these businesses do not have a defined storage system, presenting rotation and shortage problems at very specific times, which significantly affects the image of these businesses. Likewise, the percentages of this item can be seen in Figure 4.

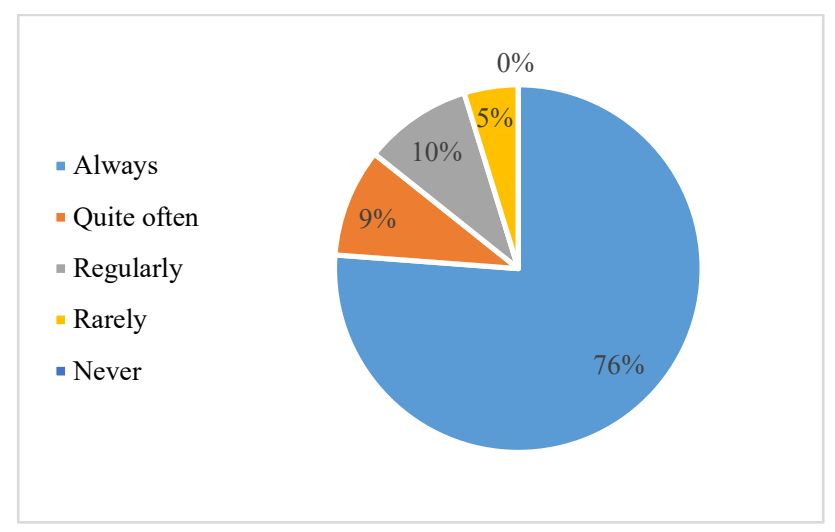

Figure 4: MSMEs that use management and administration systems in their inventories

One of the alarming results is that 16 of the 21 MSMEs diagnosed do not use or consider any inventory system to safeguard their products, which has led to shortages at some point. This can generate a negative image that severely affects MSMEs, so it is evident that it is necessary to generate a methodology for the storage of products, without having excess inventories.

- It was determined that the design of the strategic plan will follow the structure of the comprehensive strategic management model of Fred David and Forest David [2], since it is considered a fairly complete and adaptable tool, which can generate quite significant results for the achievement of competitiveness in MSMEs in the region. In Figure 5, each of the factors that make up the comprehensive strategic management model is shown in detail.

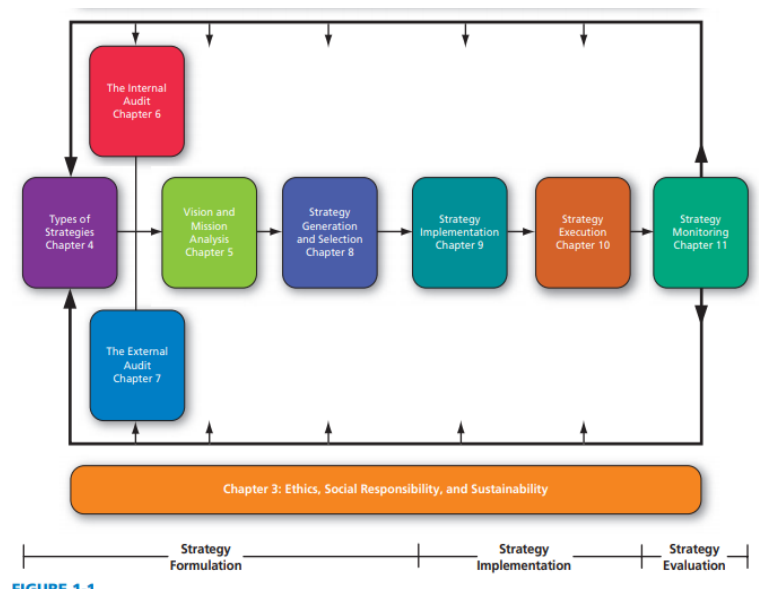

Figure 5: Fred David's Comprehensive Strategic Management Model Source: Obtained from the book "Strategic Management A Competitive Advantage Approach, Concepts and Cases" [3]. 
In this model, it is possible to obtain a vision with much more clarity about the stages of the strategies to develop; starting from the type of strategy required according to the needs detected, to then formulate a series of actions and methodologies, on which an analysis of each will be carried out and select the most appropriate according to the context in which each of MSMEs.

Once the strategies have been selected, they are carried out, monitoring the results to obtain an assessment and adjust the strategies implemented according to the evaluation obtained.

\section{Discussion}

Based on the obtained results, the relationship determined by the hypothesis is accepted, which establishes that the design of a strategic plan will make a significant contribution to achieving the competitiveness of MSMEs with respect to their large competitors. Likewise, the data found so far, show an important relationship with respect to the results shown by [6] who point out that strategic planning has a significant influence on the organizational management of MSMEs and that it can increase their competitiveness substantially.

On the other hand, in contrast to what indicate in [1], who mention that the three strategies most used by family business entrepreneurs are to improve product quality, provide a pleasant service or through the development of a new product or service that is related to the image of the business that promotes a better perception among its consumers; However, the results of this research do not agree with the previously mentioned strategies according to the diagnosed analysis unit, who do indicate that it is imperative to improve the inventory storage and control system, since considerable losses are generated in certain periods of time.

Likewise, given the integrity of the strategic management model of Fred David and Forest David, this research is expected to be too beneficial for all those MSMEs that implement the strategic plan and are in search of achieving competitiveness.

\section{Conclusions}

The lack of competitiveness is something that has affected MSMEs throughout their existence, however, not having an action plan represents a disadvantage compared to their large competitors, which does not allow them to make better use of their own resources in a more adequate way, since the low performance of competitiveness is generated mainly by the ignorance of the owners themselves, to make smarter decisions or initiatives on strategies that allow them to have greater control of their business, and in turn, help them to extend their life time in the market and allow them to grow achieving greater competitiveness.

Currently, MSMEs in the region show almost zero competitiveness and with many areas of opportunity, since they present quite a few deficiencies, among which stand out the lack of care for their equipment, the mismanagement of inventories, in addition to the worrying ignorance they have of the environment in which they compete; However, if they manage to adapt effectively to the strategies developed, they will make better use of their resources and considerably improve their processes.

For local economies, MSMEs are extremely important since they generate jobs and improve the quality of life of many people, so it is essential to promote a more equitable market, in which MSMEs can compete against large companies, achieving a greater participation in the market and generating a significant positioning among consumers in the region.

\section{Acknowledgments}

A mention of gratitude is made to all MSMEs in the region, for their willingness to carry out this research, for their approval to carry out the measurement instrument, as well as the facilities provided to know their processes and their admission to implement the relevant strategies that are developed from the diagnosis obtained; Also, a special thanks is offered to all the people who influenced the development of this research.

\section{References}

[1] M. Valenzuela, M. Monserrat., T. López, T. Virginia Guadalupe \& Moreno, M. Luis Ramón. La planeación estratégica como factor de competitividad en las empresas familiares del sector comercial del Valle de Mexicali, (article in Spanish with an abstract in English). Universidad Autónoma de Baja California, México. European Scientific Journal, 2015.

[2] G. Saavedra, M. Luisa, Milla, T. Sindy Orieta \& Tapia, S., Blanca. Determining the competitiveness of SMEs in the micro level: The case of the Federal District, Mexico, (article in Spanish with an abstract in English). Revista FIR, FAEDPYME International Review, 2(4), 38-52, 2013.

[3] F. David, \& R. David, "Strategic Management A Competitive Advantage Approach, Concepts and Cases. Sixteenth Edition. Editorial Pearson, 2017.

[4] H. Roberto \& M. Christian, "Metodología de la investigación, las rutas cuantitativa, cualitativa y mixta. Primera edición. Mc-Graw Hill, 2018.

[5] L. Montoya, S. Eduardo. "Aplicación del Mapa de Competitividad del BID a empresas del fondo emprender, (thesis in Spanish with an abstract in English). Universidad Tecnológica de Pereira, 2008.

[6] E. Mora-Rapieri, M. Vera-Colina, Z. Malgarejo-Molina "Strategic planning and competitiveness levels of SMEs in the business sector in Bogotá, (article in Spanish with an abstract in English). Revista Estudios Gerenciales, pág. 79-87, 2015. Doi: https://doi.org/10.1016/j.estger.2014.08.001.

[7] G. Saavedra, L. María \& T. Milla, "Sindy Orieta. The MSME competitiveness at the micro level: The case of Querétaro, Mexico, (article in Spanish with an abstract in English). En-Contexto Revista de Investigación en Administración, Contabilidad, Economía y Sociedad, Institución Universitaria Tecnológico de Antioquia, Colombia, 2017.

[8] S. Javier, P. José \& Uzcátegui, Carolina de los Ángeles. Metodologías de Medición de la Competitividad. II Congreso Internacional Virtual sobre desafíos de las empresas del siglo XXI, 2017. 